\title{
Improvement of Domperidone Solubility and Dissolution Rate by Dispersion in Various Hydrophilic Carriers
}

\author{
Ahmed E. Aboutaleb, Sayed I. Abdel-Rahman, Mahrous O. Ahmed, Mahmoud A. Younis* \\ Department of Industrial pharmacy, Faculty of pharmacy, Assiut University, Assiut 71526, Egypt.
}

\begin{tabular}{|c|c|}
\hline ARTICLE INFO & ABSTRACT \\
\hline Article history: & \multirow{11}{*}{$\begin{array}{l}\text { The aim of this work was to improve the solubility and dissolution rate of poorly-soluble, weakly-basic, anti- } \\
\text { emetic drug; domperidone (DMP) using solid dispersion technique. Solubility studies of DMP with various } \\
\text { hydrophilic carriers including sorbitol, mannitol, PEG } 4000 \text {, PEG } 6000 \text {, pluronic F- } 68 \text { and pluronic F- } 127 \text { were } \\
\text { performed. Pluronic F- } 68 \text { and pluronic F-127 showed the highest solubilizing effect on DMP and therefore; they } \\
\text { were selected for the preparation of solid dispersions in different weight ratios by the fusion method. The solid } \\
\text { dispersions were characterized using Fourier-transform infrared spectroscopy (FT-IR), Differential Scanning } \\
\text { Calorimetry (DSC), Powder X-ray Diffractometry (P-XRD), solubility determination and in-vitro dissolution } \\
\text { rate studies. FT-IR and DSC studies confirmed the absence of incompatibilities between DMP and the used } \\
\text { carriers. DSC and P-XRD studies proved the transformation of drug from crystalline to amorphous state in the } \\
\text { prepared solid dispersions. The results showed marked improvement of DMP solubility and dissolution rate } \\
\text { from the solid dispersions compared with the pure drug and indicated the superiority of solid dispersions } \\
\text { prepared with pluronic F- } 68 \text { over those prepared with pluronic F-127. It can be concluded that solid dispersion } \\
\text { technique was an effective tool in the enhancement of DMP dissolution. }\end{array}$} \\
\hline Received on: $11 / 03 / 2016$ & \\
\hline Revised on: $13 / 04 / 2016$ & \\
\hline Accepted on: 19/05/2016 & \\
\hline Available online: $28 / 07 / 2016$ & \\
\hline Key words: & \\
\hline Domperidone, Solubility, & \\
\hline Pluronic, Solid dispersions, & \\
\hline dissolution. & \\
\hline & \\
\hline & \\
\hline
\end{tabular}

\section{INTRODUCTION}

Solubility is a significant physico-chemical parameter affecting the absorption and therapeutic efficacy of any drug. The low aqueous solubility and dissolution rate of drug substances frequently lead to inadequate absorption and low bioavailability. So, improvement of the solubility and dissolution rate of hydrophobic drugs has a critical importance in the formulation development process (Dalvi et al., 2015). Several approaches have been developed to solve this problem. Solid dispersion technique has become one of the most promising attitudes in the drug solubilization process. A solid dispersion can be defined as a "dispersion of drug within inert hydrophilic carrier in the solid state". Formulation of solid dispersion leads to improvement of the wettability and surface area of drug with consequent enhancement of solubility, dissolution rate, absorption and

\section{* Corresponding Author}

Mahmoud A. Younis, Department of Industrial pharmacy, Faculty of pharmacy, Assiut University, Assiut 71526, Egypt.

Email:mahmoud_ab32@yahoo.com bioavailability (Dhirendra et al., 2009; Singh et al., 2011; Huang and Dai, 2014). Domperidone (DMP) is 5-chloro-1-[1-[3-(2, 3dihydro-2-oxo-1H-benzimidazol-1-yl)-propyl] 4-piperidinyl]-1, 3dihydro-2H-benzimidazol-2-one. It is a dopamine $\left(\mathrm{D}_{2}\right)$ receptor antagonist. DMP is used for the treatment and prevention of acute nausea and vomiting of any cause; especially cytotoxic therapy and radiotherapy (Reddymasu et al., 2007). According to Biopharmaceutical Classification System (BCS), DMP is categorized under class II drugs which are poorly water-soluble and highly permeable (Swami et al., 2010; Zhang et al., 2011). It is practically insoluble in water (1 part in 50,000 part of water) (Council of Europe, 2014) and has a pka value of 7.9 so, it is a weakly-basic drug with a very poor dissolution rate at relativelyhigh $\mathrm{pH}$ values. This makes the absorption of drug dissolution ratelimited and lowers its bioavailability to $13-17 \%$ after oral administration (Swami et al., 2010; Zhang et al., 2011). Moreover, the poor solubility and dissolution rate of DMP at elevated $\mathrm{pH}$ values limit the ability for its delivery via rectal or buccal routes and necessitate the use of powerful solubilization techniques (Ibrahim et al., 2012; Patel et al., 2012). 
In the present work, DMP was solubilized using solid dispersion technique to enhance its dissolution rate and consequently, the bioavailability. The authors selected to focus solubility and dissolution studies at $\mathrm{pH} 6.8$ to facilitate further incorporation of the optimized formulae into buccal or sublingual dosage forms in the future work which would be promising in overcoming the first-pass metabolism associated with oral administration of DMP (Bardal et al., 2011).

Solubility studies of DMP with several hydrophilic carriers including sorbitol, mannitol, PEG 4000, PEG 6000, pluronic F-68 and pluronic F-127 were performed to select the best carriers for the formulation of solid dispersions. Pluronic F-68 and pluronic F-127 showed the best results and were selected as carriers for drug in the solid dispersions. Solid dispersions were prepared by fusion method in different weight ratios and were characterized for their physico-chemical properties using Fouriertransform infrared spectroscopy (FT-IR), Differential Scanning Calorimetry (DSC), Powder X-ray Diffractometry (P-XRD), solubility studies and in-vitro dissolution rate studies.

\section{MATERIALS AND METHODS}

\section{Materials}

Domperidone was kindly supplied as a gift sample by Pharco, for pharmaceutical and chemical industry, Egypt. Sorbitol and mannitol were purchased from Cooperation Pharmaceutique Francaise, France. Polyethylene glycol 4000 (PEG 4000) and polyethylene glycol 6000 (PEG 6000) were purchased from Merck-Schuchardt, Germany. Pluronic F-68 and pluronic F-127 were purchased from "Sigma Aldrich Co.", USA.

\section{Methods}

\section{Solubility studies on DMP}

Determination of equilibrium aqueous solubility of DMP

Equilibrium aqueous solubility of DMP was determined by placing an excess amount of DMP in stoppered glass flasks containing $10 \mathrm{ml}$ of distilled water. The solutions were shaken at a rate of $(40 \pm 2)$ stroke/minute in a thermostatically-controlled water bath (DAIHAN scientific company-model WSB-45, Korea) at $37 \pm 0.5^{\circ} \mathrm{C}$ for 24 hours. After suitable time intervals $(1,2,3,4,5$, 6 and 24 hours), samples of $1 \mathrm{ml}$ were withdrawn from each test solution, filtered immediately and assayed spectrophotometrically at $\lambda_{\max }$ of $284 \mathrm{~nm}$ for the solubilized DMP content. It was found that the equilibrium solubility of DMP was reached after 2 hours.

\section{Determination of $\mathrm{pH}$-solubility profile of DMP}

An excess amount of DMP was placed in stoppered glass flasks containing $10 \mathrm{ml}$ of buffer solutions with $\mathrm{pH} \mathrm{1.2,} \mathrm{5,} 6.8$ and 7. The solutions were shaken at a rate of $(40 \pm 2)$ stroke/minute in a thermostatically-controlled water bath at $37 \pm 0.5{ }^{\circ} \mathrm{C}$ for 2 hours. Samples of $1 \mathrm{ml}$ were withdrawn from each test solution, filtered immediately and assayed spectrophotometrically at $\lambda_{\max }$ of $284 \mathrm{~nm}$ for the solubilized DMP content. The solubility values were plotted versus the corresponding $\mathrm{pH}$ of the solutions to obtain the $\mathrm{pH}$-solubility profile.

\section{Effect of different hydrophilic carriers on the solubility of DMP}

An excess amount of DMP was placed in stoppered glass flasks containing $10 \mathrm{ml}$ of phosphate buffer solution (pH 6.8) and different concentrations $(1,5,10,15$ and $20 \% \mathrm{w} / \mathrm{v})$ of sorbitol, mannitol, PEG 4000, PEG 6000, pluronic F-68 and pluronic F127. The solutions were shaken at a rate of $(40 \pm 2)$ stroke/minute in a thermostatically-controlled water bath at $37 \pm 0.5{ }^{\circ} \mathrm{C}$ for 2 hours. Samples of $1 \mathrm{ml}$ were withdrawn from each test solution, filtered immediately and assayed spectrophotometrically at $\lambda_{\max }$ of $284 \mathrm{~nm}$ for the solubilized DMP content. Experiments were carried out in triplicates and the average was considered. It was found that pluronic F-68 and pluronic F-127 exerted the highest solubilizing effect on DMP and thus; they were selected for the formulation of solid dispersions.

\section{Preparation of DMP solid dispersions}

Solid dispersions of DMP with pluronic F-68 and pluronic F-127 were prepared in weight ratios of 1:1, 1:3, 1:5 and $1: 7 \mathrm{w} / \mathrm{w}$ by fusion method. The calculated amount of carrier was placed in a porcelain dish and heated till melting over steam bath. The accurately weighed amount of DMP was dispersed into molten carrier gradually using a glass rod. After complete dispersion of drug within carrier, the dish was removed from steam bath and left aside to cool at room temperature till solidification of its contents. Then, the solid dispersion formed was pulverized, sieved to obtain a particle size range of 125-250 $\mu \mathrm{m}$ and stored in a dessicator over calcium chloride till used.

\section{Characterization of the prepared solid dispersions Drug content}

An accurately weighed amount of the prepared solid dispersions equivalent to $10 \mathrm{mg}$ of the drug was added to $100 \mathrm{ml}$ volumetric flask, dissolved in minimum amount of methanol and the volume was completed to $100 \mathrm{ml}$ with phosphate buffer ( $\mathrm{pH}$ 6.8). After suitable dilution, DMP content was determined spectrophotometrically at $284 \mathrm{~nm}$. Only those samples containing $100 \pm 5 \%$ of the claimed amount of DMP were considered for further studies.

\section{Fourier-transform infrared (FT-IR) studies}

A qualitative FT-IR analysis was performed for drug, carriers and the prepared solid dispersions. Samples of 1-2 mg were mixed with potassium bromide (IR grade) and compressed into discs in a compressor unit under vacuum and then scanned from 4000 to $400 \mathrm{~cm}^{-1}$ using FT-IR spectrometer (Shimadzu IR470, Japan), with an empty pellet holder as a reference.

\section{Differential Scanning Calorimetry (DSC) studies}

DSC thermograms for drug, carriers and the prepared solid dispersions were obtained by using a shimadzu DSC-50 (Japan) equipped with a software computer program. Samples of 
about $5 \mathrm{mg}$ were placed in an aluminum pan of $50 \mu \mathrm{l}$ capacity and $0.1 \mathrm{~mm}$ thickness, press-sealed with aluminum cover of $0.1 \mathrm{~mm}$ thickness. An empty pan sealed in the same way was used as a reference. Samples were heated from $30{ }^{\circ} \mathrm{C}$ to $300{ }^{\circ} \mathrm{C}$ at a rate of $10{ }^{\circ} \mathrm{C} \mathrm{min}{ }^{-1}$ and nitrogen flow of $25 \mathrm{ml} / \mathrm{min}$. Indium was used as a standard for calibrating temperature. Thermograms obtained were analyzed using TA-50 program to determine temperature and heat of fusion $(\Delta \mathrm{H})$ for each peak.

\section{Powder X-ray diffractometry $(P$-XRD) studies}

The X-ray diffractograms for drug, carriers and the prepared solid dispersions were obtained using Philips 1710 diffractometer (Germany). The target was $\mathrm{CuK \alpha}$ radiation operating at $40 \mathrm{KV}$ and a current of $40 \mathrm{~mA}$ and a single crystal graphite monochromator was used. The diffraction patterns were achieved using continuous scan mode with $2 \theta$ ranging from $4^{\circ}$ to $60^{\circ}$ at a rate of $0.6 \% \mathrm{~min}$.

\section{Solubility studies on the prepared solid dispersions}

Solubility of the prepared solid dispersions in phosphate buffer solution ( $\mathrm{pH}$ 6.8) was determined by placing an excess amount of the investigated solid dispersions in stoppered glass flasks containing $10 \mathrm{ml}$ of phosphate buffer solution ( $\mathrm{pH} \mathrm{6.8).} \mathrm{The} \mathrm{solutions} \mathrm{were} \mathrm{shaken} \mathrm{at} \mathrm{a} \mathrm{rate} \mathrm{of} \mathrm{(40 \pm 2)}$ stroke/minute in a thermostatically-controlled water bath at $37 \pm 0.5$ ${ }^{\circ} \mathrm{C}$ for 2 hours. Samples of $1 \mathrm{ml}$ were withdrawn from each test solution, filtered immediately and assayed spectrophotometrically at $\lambda_{\max }$ of $284 \mathrm{~nm}$ for the solubilized DMP content. Experiments were carried out in triplicates and the average was considered.

\section{In-vitro dissolution rate studies}

USP dissolution apparatus II (paddle type) (Erweka DTD6, Heusenstamm, Germany) was used at a rotation speed of 50 r.p.m. Powdered samples of each preparation equivalent to 10 $\mathrm{mg}$ of domperidone were added to the dissolution medium $(500 \mathrm{ml}$ phosphate buffer solution with $\mathrm{pH} 6.8$, kept at $37 \pm 0.5^{\circ} \mathrm{C}$ ). Pure drug was sieved to obtain a size range of $125-250 \mu \mathrm{m}$ and treated similarly. At time intervals of 5, 15, 30, 45, 60, 90 and 120 minutes, samples $(5 \mathrm{ml})$ of the solution were withdrawn with a volumetric pipette, using cotton plug as a filter and replaced with an equal volume of fresh dissolution medium equilibrated at 37 ${ }^{\circ} \mathrm{C}$. The samples were analyzed spectrophotometrically at $\lambda_{\max }$ of $284 \mathrm{~nm}$. Each experiment was performed in triplicates, and the mean recordings were used for calculations.

\section{RESULTS AND DISCUSSION}

\section{Solubility studies on DMP}

\section{Determination of equilibrium aqueous solubility of DMP}

Equilibrium solubility of DMP in distilled water was achieved after 2 hours and was equal to $5.09 \pm 0.24 \mu \mathrm{g} / \mathrm{ml}$ (Fig.1). This low solubility confirmed that DMP was practically-insoluble in water (Council of Europe, 2014).

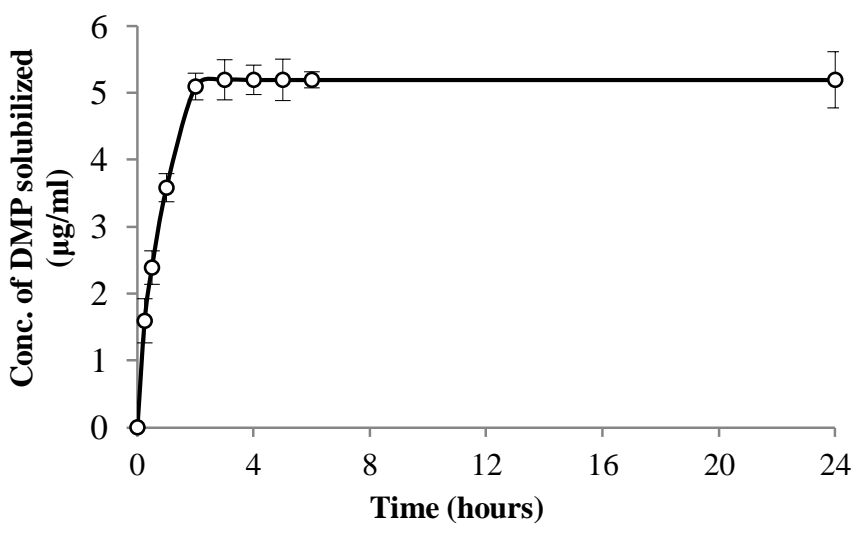

Fig. 1: Equilibrium aqueous solubility of DMP.

\section{Determination of $\mathrm{pH}$-solubility profile of $\mathrm{DMP}$}

Table (1) and Fig. (2) show the pH-solubility profile of DMP. It was obvious that DMP solubility was markedly decreased by increasing $\mathrm{pH}$ of the solution. This could be attributed to the weakly-basic nature of DMP (pka $=7.9$ ) favoring low $\mathrm{pH}$ values for drug ionization and solubilization (Aboutaleb et al., 2016).

Table 1: $\mathrm{pH}$ solubility profile of DMP

\begin{tabular}{cc}
\hline pH value & DMP Solubility $(\boldsymbol{\mu g} / \mathbf{m l})$ \\
\hline 1.2 & $578 \pm 15.5$ \\
5 & $200 \pm 2.50$ \\
6.8 & $21 \pm 1.15$ \\
7 & $5.09 \pm 0.24$ \\
\hline
\end{tabular}

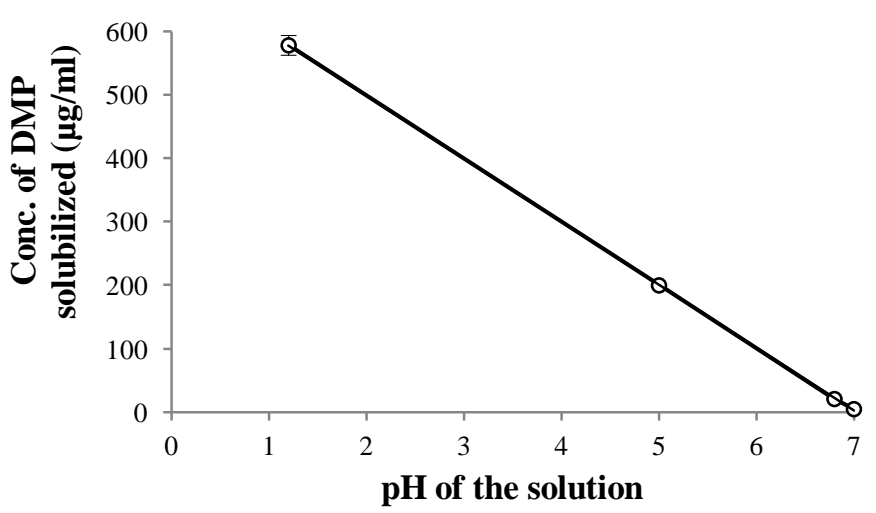

Fig. 2: $\mathrm{pH}$ solubility profile of DMP.

\section{Effect of different hydrophilic carriers on the solubility of DMP}

Table (2) and Fig. (3) show the effect of different concentrations of hydrophilic carriers on the solubility of DMP in a phosphate buffer solution of $\mathrm{pH}$ 6.8. The results revealed that addition of hydrophilic carriers to the solution increased the solubility of DMP. This can be attributed to the hydrogen bonding interactions between drug and carrier leading to improved solubility (Rojas-Oviedo et al., 2012). Increasing the concentration of carrier in solution, the solubilizing effect on DMP increased. It was obvious that pluronic F-68 and pluronic F-127 exerted the highest solubilizing effect on DMP among all investigated carriers due to their higher aqueous solubilities and Hydrophilic Lipophilic Balance (HLB) values (Devi et al., 2013) and thus; they were selected for the formulation of solid dispersions. 
Table 2: Effect of different concentrations of hydrophilic carriers on the solubility of DMP in a phosphate buffer solution of pH 6.8 .

\begin{tabular}{ccccccc}
\hline $\begin{array}{c}\text { Carrier conc. } \\
(\% \text { w/v })\end{array}$ & PEG 4000 & PEG 6000 & Sorbitol & Mannitol & $\begin{array}{c}\text { Pluronic } \\
\text { F-127 }\end{array}$ & $\begin{array}{c}\text { Pluronic } \\
\text { F-68 }\end{array}$ \\
\cline { 2 - 7 } & & & $0.0021 \pm 0.0003$ & $0.0021 \pm 0.0003$ & $0.0021 \pm 0.0003$ & $0.0021 \pm 0.0003$ \\
1 & $0.0021 \pm 0.0003$ & $0.0029 \pm 0.0017$ & $0.0024 \pm 0.0009$ & $0.0051 \pm 0.0002$ & $0.0021 \pm 0.0003$ \\
5 & $0.0091 \pm 0.0005$ & $0.0033 \pm 0.0004$ & $0.0076 \pm 0.0008$ & $0.0062 \pm 0.0012$ & $0.0046 \pm 0.0019$ & $0.0111 \pm 0.0015$ \\
10 & $0.0147 \pm 0.0004$ & $0.0126 \pm 0.0010$ & $0.0105 \pm 0.0022$ & $0.0075 \pm 0.0013$ & $0.0166 \pm 0.0014$ & $0.0131 \pm 0.0015$ \\
15 & $0.0213 \pm 0.0015$ & $0.0183 \pm 0.0015$ & $0.0148 \pm 0.0014$ & $0.0105 \pm 0.0015$ & $0.0233 \pm 0.0015$ & $0.0263 \pm 0.0018$ \\
20 & $0.0271 \pm 0.0022$ & $0.0233 \pm 0.0040$ & $0.0190 \pm 0.0023$ & $0.0134 \pm 0.0025$ & $0.0299 \pm 0.0042$ & $0.0329 \pm 0.0013$ \\
\hline 0
\end{tabular}
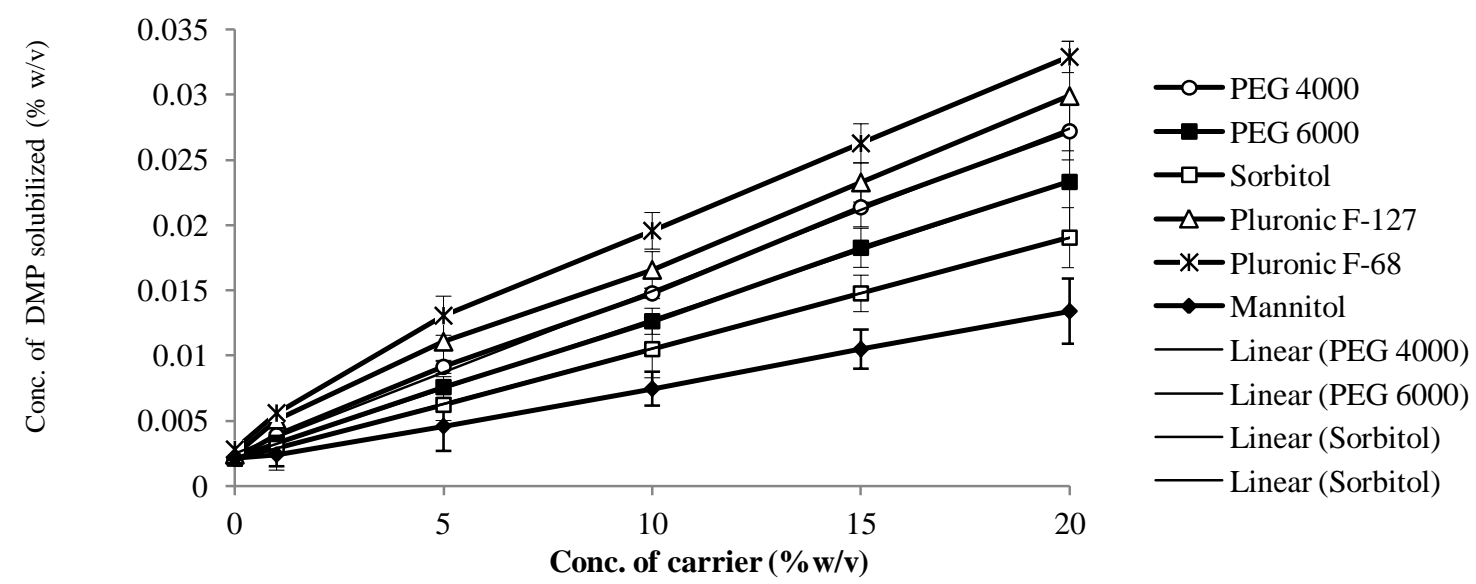

Fig. 3: Effect of different hydrophilic carriers on the solubility of DMP in phosphate buffer solution (pH 6.8).

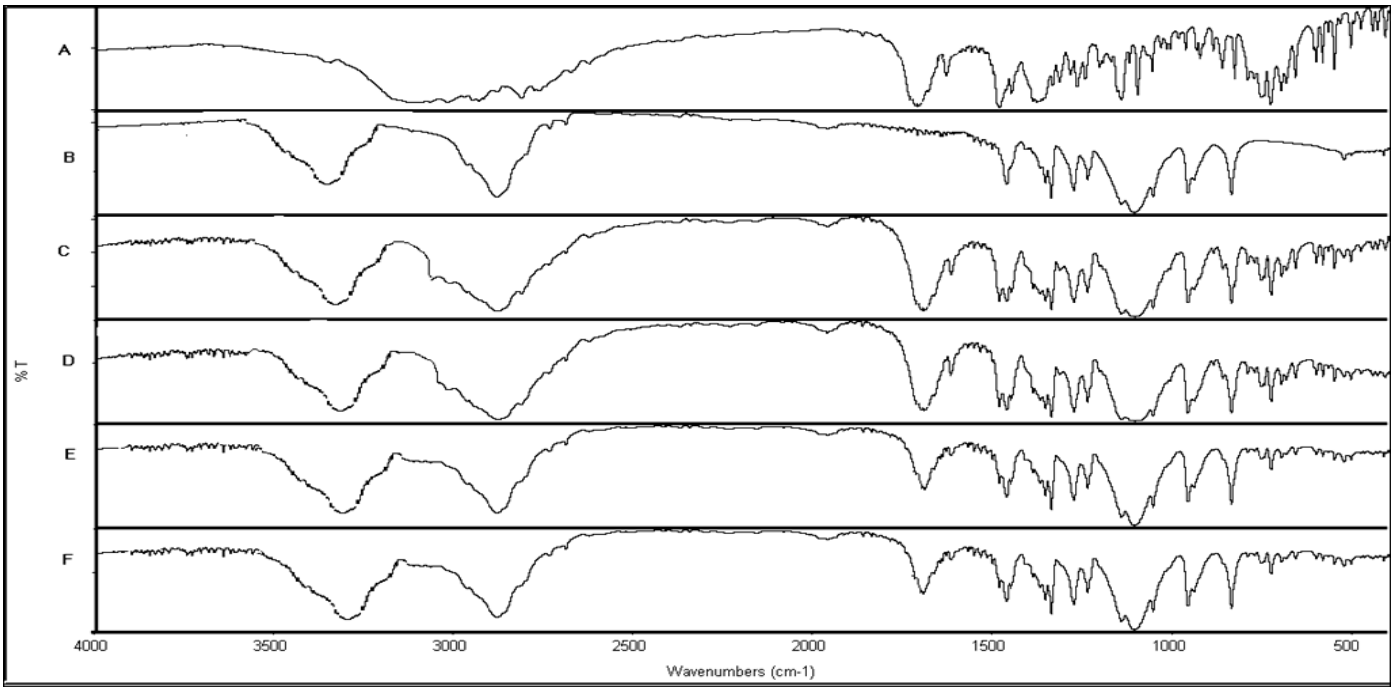

Fig. 4: FT-IR spectra of DMP-Pluronic F-68 solid dispersions. DMP (A), pluronic F-68 (B), 1:1 (w/w) solid dispersion (C), 1:3 (w/w) solid dispersion (D), $1: 5$ $(\mathrm{w} / \mathrm{w})$ solid dispersion $(\mathrm{E})$ and 1:7 (w/w) solid dispersion $(\mathrm{F})$.

\section{Characterization of the prepared solid dispersions Drug content}

The results showed slight differences between theoretical and actual DMP contents in the prepared solid dispersions $(98 \pm 2$ $\%)$ which might be due to loss of drug during pulverization and sieving processes. The results were acceptable and the samples were considered for further studies.

\section{Fourier-transform infrared (FT-IR) studies}

FT-IR spectra of DMP-pluronic F-68 systems are shown in Fig.(4). DMP (trace A) showed characteristic bands at $1697 \mathrm{~cm}^{-}$ ${ }^{1}\left(\mathrm{C}=\mathrm{O}\right.$ stretching vibration), 3300-3500 $\mathrm{cm}^{-1}$ (N-H stretching vibration), $3000-3100 \mathrm{~cm}^{-1}$ (aromatic $=\mathrm{C}-\mathrm{H}$ stretching vibration),
$2850-3000 \mathrm{~cm}^{-1}\left(\mathrm{sp}^{3}-\mathrm{C}-\mathrm{H}\right.$ vibration) and several bands at 1400 $1600 \mathrm{~cm}^{-1}$ (aromatic $\mathrm{C}=\mathrm{C}$ stretching vibration). Pluronic F-68 (Fig. 4 , trace B) showed characteristic bands at $3200-3600 \mathrm{~cm}^{-1}$ (broad band for $\mathrm{O}-\mathrm{H}$ stretching vibration) and $2850-3000 \mathrm{~cm}^{-1}\left(\mathrm{sp}^{3}-\mathrm{C}-\mathrm{H}\right.$ vibration). Solid dispersions (Fig. 4, traces C, D, E and F) showed the same characteristic bands of DMP and pluronic F-68 without significant changes confirming the absence of incompatibilities between them.

Increasing the amount of pluronic F-68 in the solid dispersion, the absorption band of $\mathrm{C}=\mathrm{O}$ group of DMP became more broad and decreased in intensity due to dilution effect (Aboutaleb et al., 2016). Similar results were obtained with DMPpluronic F-127 systems. 


\section{Differential Scanning Calorimetry (DSC) studies}

DSC thermograms of DMP-pluronic F-68 systems are shown in Fig.(5). DMP (Fig. 5, trace A) showed a sharp endothermic peak at $252.49{ }^{\circ} \mathrm{C}$ corresponding to its melting point (Council of Europe, 2014) with a fusion enthalpy $(\Delta \mathrm{H})$ of $(-94.37)$ J/g. Pluronic F-68 (Fig. 5, trace B) showed a sharp endothermic peak at $53.68{ }^{\circ} \mathrm{C}$ corresponding to its melting point (Rowe et al., 2009) with a fusion enthalpy of (-84.33) $\mathrm{J} / \mathrm{g}$. The characteristic endothermic peak of DMP was completely disappeared in the solid dispersions (Fig. 5, traces C, D, E and F) suggesting that drug might be transformed from crystalline state to amorphous state (Garg et al., 2013) which was confirmed by powder X-ray diffractometry studies (P-XRD) as indicated below. Similar results were obtained with DMP-pluronic F-127 systems.

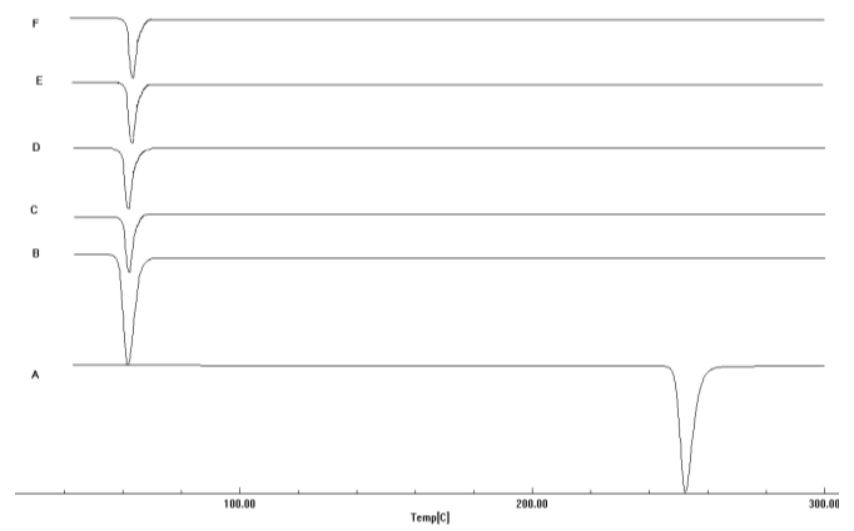

Fig. 5: DSC thermograms of DMP-Pluronic F-68 solid dispersions. DMP (A), pluronic F-68 (B), 1:1 (w/w) solid dispersion (C), 1:3 (w/w) solid dispersion (D), 1:5 (w/w) solid dispersion (E) and 1:7 (w/w) solid dispersion (F).

\section{Powder X-ray diffractometry $(P-X R D)$ studies}

Figure (6) shows powder X-ray diffractograms of DMPpluronic F-68 systems. Pure drug (Fig.6, trace A) and pluronic F68 (Fig.6, trace B) showed strong peaks of crystallinity indicating the presence of both pure drug and carrier in the crystalline state. In solid dispersions (Fig.6, traces C, D, E and F), carrier peaks were decreased in intensity due to reduction of crystallinity while the drug peaks were completely disappeared confirming the transformation of DMP from the crystalline state to the amorphous state (El-Badry et al., 2013) in these systems as suggested from
DSC results mentioned before. Similar results were obtained with DMP-pluronic F-127 systems.
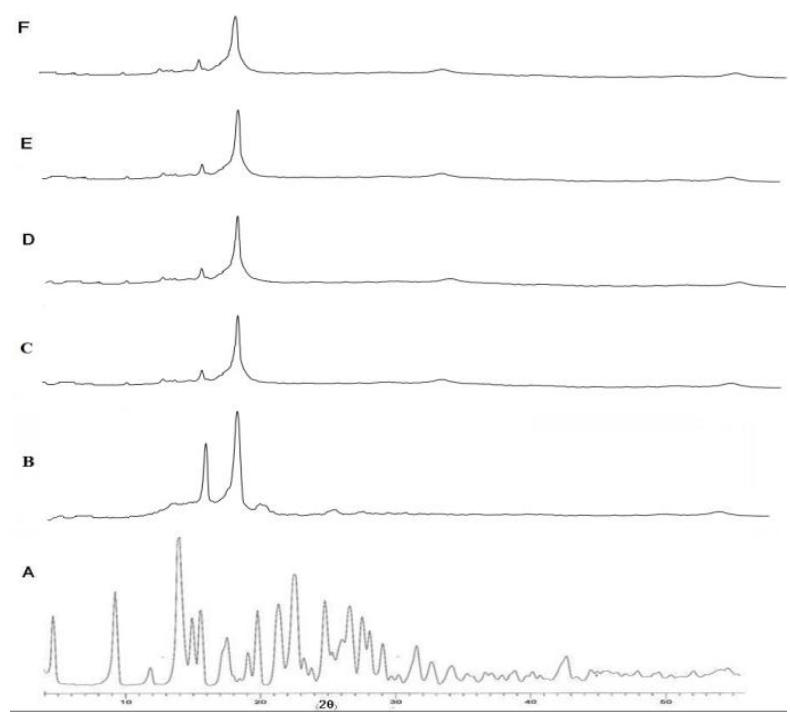

Fig. 6: Powder X-ray diffractograms of DMP-pluronic F-68 solid dispersions. DMP (A), pluronic F-68 (B), 1:1 (w/w) solid dispersion (C), 1:3 $(\mathrm{w} / \mathrm{w})$ solid dispersion $(D), 1: 5(\mathrm{w} / \mathrm{w})$ solid dispersion $(\mathrm{E})$ and 1:7 $(\mathrm{w} / \mathrm{w})$ solid dispersion $(\mathrm{F})$.

\section{Solubility studies for the prepared solid dispersions}

Table (3) and Fig. (7) show the effect of different solid dispersions prepared with pluronic F-68 on the solubility of DMP at $\mathrm{pH}$ 6.8. It was obvious that the solid dispersions resulted in marked enhancement of DMP solubility. This can be explained as when solid dispersions are exposed to aqueous media, the carrier dissolves, and the drug is released as very fine colloidal particles. This greatly reduces particle size and increases surface area, which results in improved solubility (Kalyanwat and Patel, 2010). Increasing the amount of carrier in the solid dispersion resulted in further improvement of the drug solubility. Solid dispersions prepared with pluronic F-68 showed higher solubilization of DMP than those prepared with pluronic F-127 (Table 4 and Fig. 8). This can be attributed to the higher aqueous solubility and HLB value of pluronic F-68 than pluronic F-127 (HLB values are 29 and 22 for pluronic F-68 and pluronic F-127, respectively) leading to enhanced wettability of drug (Türk et al., 2009).

Table 3: Effect of different solid dispersions prepared with pluronic F-68 on the solubility of DMP at pH 6.8 .

\begin{tabular}{|c|c|c|c|c|c|}
\hline \multirow{3}{*}{ Time (hr) } & \multicolumn{5}{|c|}{ Concentration of DMP Solubilized $(\mu \mathrm{g} / \mathrm{ml})$} \\
\hline & \multirow{2}{*}{ DMP alone } & \multicolumn{4}{|c|}{ DMP-pluronic F-68 solid dispersions } \\
\hline & & 1:1 & $1: 3$ & $1: 5$ & 1:7 \\
\hline 0.25 & $6.99 \pm 0.71$ & $23.31 \pm 1.45$ & $54.39 \pm 2.24$ & $104.89 \pm 3.30$ & $143.74 \pm 2.40$ \\
\hline 0.50 & $8.55 \pm 0.53$ & $27.19 \pm 2.15$ & $66.04 \pm 2.06$ & $116.55 \pm 1.75$ & $155.40 \pm 3.44$ \\
\hline 1 & $13.60 \pm 1.40$ & $34.96 \pm 2.65$ & $93.24 \pm 1.95$ & $143.74 \pm 3.10$ & $182.59 \pm 2.71$ \\
\hline 2 & $21 \pm 1.15$ & $48.56 \pm 1.55$ & $112.66 \pm 2.10$ & $174.82 \pm 2.80$ & $221.44 \pm 4.45$ \\
\hline
\end{tabular}

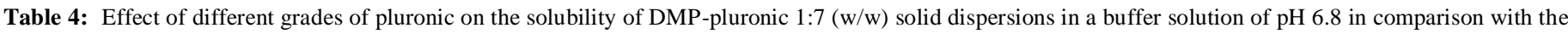
pure drug.

\begin{tabular}{|c|c|c|c|}
\hline \multirow{3}{*}{ Time (hr) } & \multicolumn{3}{|c|}{ Concentration of DMP Solubilized $(\mu \mathrm{g} / \mathrm{ml})$} \\
\hline & \multirow{2}{*}{ DMP alone } & \multicolumn{2}{|c|}{ DMP-pluronic 1:7 (w/w) solid dispersions } \\
\hline & & Pluronic F-127 & Pluronic F-68 \\
\hline 0.25 & $6.99 \pm 0.71$ & $124.32 \pm 1.52$ & $143.74 \pm 2.40$ \\
\hline 0.5 & $8.55 \pm 0.53$ & $135.97 \pm 2.55$ & $155.40 \pm 3.44$ \\
\hline 1 & $13.60 \pm 1.40$ & $163.17 \pm 1.81$ & $182.59 \pm 2.71$ \\
\hline 2 & $21 \pm 1.15$ & $202.02 \pm 3.38$ & $221.44 \pm 4.45$ \\
\hline
\end{tabular}




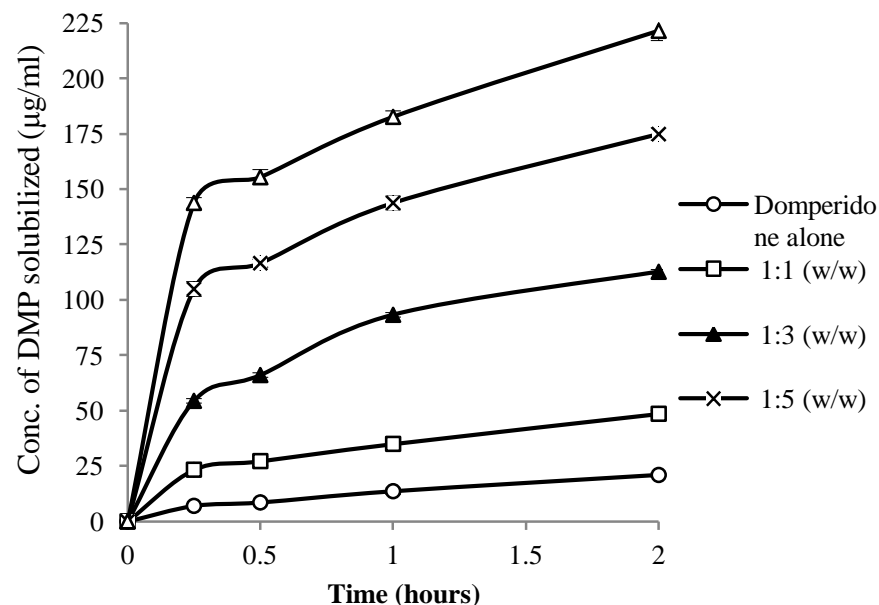

Fig. 7: Effect of different solid dispersions prepared with pluronic F-68 on the solubility of DMP in a phosphate buffer solution of $\mathrm{pH} 6.8$ in comparison with the pure drug.

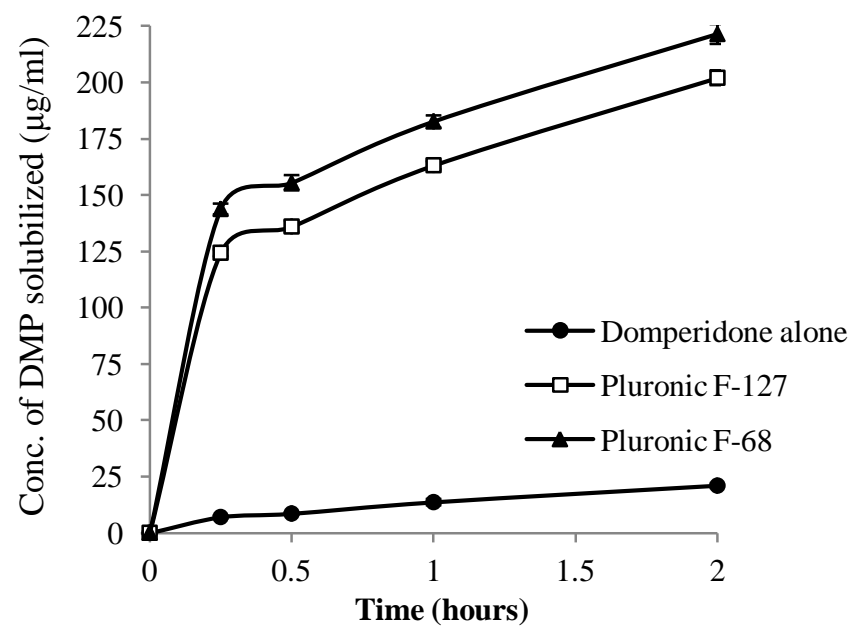

Fig. 8: Effect of different grades of pluronic on the solubility of DMPpluronic $1: 7(\mathrm{w} / \mathrm{w})$ solid dispersions in a buffer solution of $\mathrm{pH} 6.8$ in comparison with the pure drug.

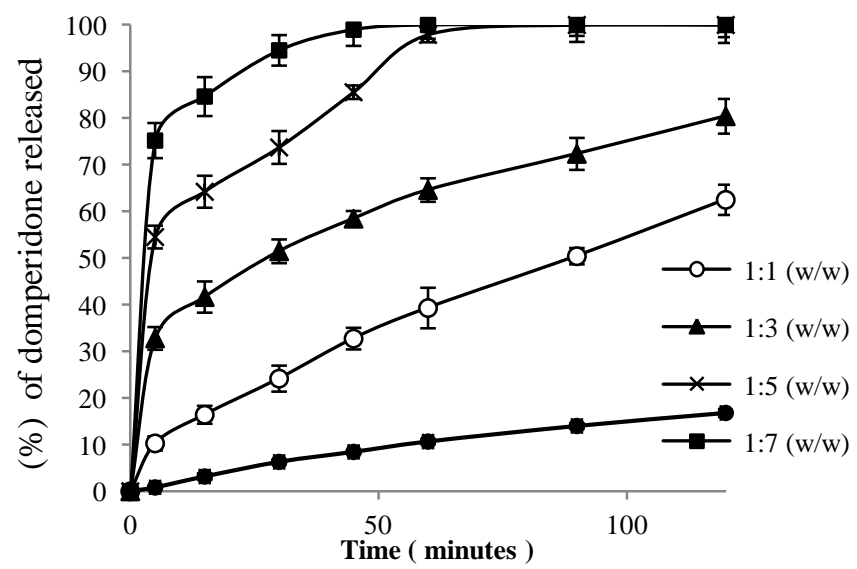

Fig. 9: Release profiles of DMP from its different solid dispersions prepared with pluronic F-68 in a phosphate buffer solution of $\mathrm{pH} 6.8$ in comparison with the pure drug.

\section{In-vitro dissolution rate studies}

Figure (9) show the release profiles of DMP from the different solid dispersions prepared with pluronic F-68 in comparison with the pure drug. It was obvious that all solid dispersions showed higher dissolution rate than the pure drug. This can be attributed to many reasons including: the enhancement of drug solubility, increased surface area of drug as well as the transformation of drug from the crystalline state to the amorphous state which has higher solubility and dissolution rate (Kalyanwat and Patel, 2010; Khadka et al., 2014). Increasing the amount of carrier in the solid dispersion increased the dissolution rate. Solid dispersions prepared with pluronic F-68 showed higher dissolution rate than those prepared with pluronic F-127 (Fig. 10) due to the higher aqueous solubility and HLB value of pluronic F-68 than pluronic F-127 with consequent enhancement of drug wettability (Türk et al., 2009).

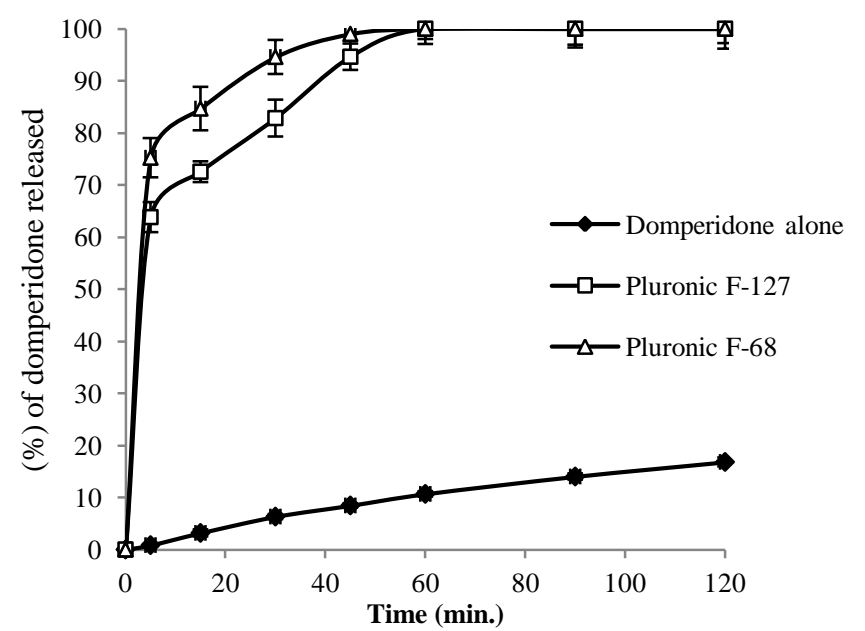

Fig. 10: Effect of different grades of pluronic on the release profiles of DMP from its 1:7 (w/w) solid dispersions in a phosphate buffer solution of $\mathrm{pH} 6.8$ in comparison with the pure drug.

\section{CONCLUSION}

DMP solubility was $\mathrm{pH}$-dependent and more favored at low $\mathrm{pH}$ values. The use of hydrophilic carriers resulted in enhancement of DMP solubility and this enhancement was dependent on the type and concentration of carrier. Pluronic F-127 and pluronic F-68 exerted the highest solubilizing effect on DMP and they were selected for the formulation of solid dispersions. FT-IR studies confirmed the absence of incompatibilities between DMP and pluronics. DSC and P-XRD studies confirmed the transformation of DMP from the crystalline state to the amorphous state in the prepared solid dispersions which lead to enhancement of drug solubility and dissolution rate. Formulation of solid dispersions resulted in marked improvement of the solubility and dissolution rate of DMP. Increasing the amount of carrier in the system resulted in further enhancement of solubility and dissolution rate. Solid dispersions prepared with pluronic F-68 showed higher solubility and dissolution rate than those prepared with pluronic F-127. The previous results revealed that solid dispersion technology was an effective tool in the solubilization of DMP and the prepared solid dispersions could be promising for further incorporation into many dosage forms including those intended for buccal or sublingual administration. 


\section{CONFLICT OF INTERESTS}

The authors report no conflict of interests in this work.

\section{ACKNOWLEDGEMENT}

The authors are grateful to Faculty of Pharmacy, Assiut University, Egypt for supporting and facilitating the work. Also, the authors are grateful to Pharco, for pharmaceutical and chemical industry, Egypt for gifting domperidone.

\section{REFERENCES}

Aboutaleb AE, Abdel-Rahman SI, Ahmed MO, Younis MA. Enhancement of domperidone dissolution rate via formulation of adsorbates and co-adsorbates. Int J Pharm Sci Res, 2016; 7: 951-60.

Bardal SK, Waechter JE, Martin DS. 2011. Applied pharmacology. Missouri, USA: Elsevier Saunders.

Council of Europe. 2014. Domperidone. In: European Pharmacopoeia. Strasbourg: European Directorate for the Quality of Medicines and Health Care 2095-6.

Dalvi PB, Gerange AB, Ingale PR. Solid dispersion: strategy to enhance solubility. J Drug Deliv Therapeut, 2015; 5: 20-8.

Devi DR, Sandhya P, Hari BNV. Poloxamer: A novel functional molecule for drug delivery and gene therapy. J Pharm Sci Res, 2013; 5: 159-65.

Dhirendra K, Lewis S, Udupa N, Atin K. Solid dispersions: A review. Pak J Pharm Sci, 2009; 22: 234-46.

El-Badry M, Hassan MA, Ibrahim MA, ELsaghir $\mathrm{H}$. Performance of poloxamer 407 as hydrophilic carrier on the binary mixtures with nimesulide. Farmacia, 2013; 61: 1137-50.

Garg AK, Sachdeva RK, Kapoor G. Comparison of crystalline and amorphous carriers to improve the dissolution profile of water insoluble drug itraconazole. Int J Pharm Bio Sci, 2013; 4: 934-48.

Huang Y, Dai W. Fundamental aspects of solid dispersion technology for poorly soluble drugs. Acta Pharm Sinica B, 2014; 4: 18-25. Ibrahim EH, El-Faham TH, Mohammed FA, El-Eraky NS. Formulation, in-vitro release and bioavailability study of domperidone rectal suppositories. Int J Innovations Pharm Sci, 2012; 1: 8-14.
Kalyanwat R, Patel S. Solid dispersion: A method for enhancing drug dissolution. Int J Drug Formul Res, 2010; 1: 1-14.

Khadka P, Ro J, Kim Hyeongmin, Kim I, Kim JT, Kim Hyunil, Cho JM, Yun G, Lee J. Pharmaceutical particle technologies: An approach to improve drug solubility, dissolution and bioavailability. Asian J Pharm Sci, 2014; 9: 304-16.

Patel RB, Patel KR, Patel MR, Patel NM. Formulation and invitro evaluation of mucoadhesive buccal tablet of domperidone. Pharm Sci Monitor, 2012; 3: 2532 -58.

Reddymasu SC, Soykan I, McCallum RW. Domperidone: review of pharmacology and clinical applications in gastroenterology. Am J Gastroenterol, 2007; 102: 2036-45.

Rojas-Oviedo I, Retchkiman-Corona B, Quirino-Barreda CT, Cárdenas J, Schabes-Retchkiman PS. Solubility enhancement of a poorly water soluble drug by forming solid dispersions using mechanochemical activation. Indian J Pharm Sci, 2012; 74: 505-11.

Rowe RC, Sheskey PJ, Quinn ME. 2009. Handbook of pharmaceutical excipients. 6th ed. London, UK: Pharmaceutical Press.

Singh S, Baghel RS, Yadav L. A review on solid dispersion. Int J Pharm Life Sci, 2011; 2: 1078-95.

Swami G, Koshy MK, Pandey M, Saraf SA. Preparation and characterization of domperidone- $\beta$-cyclodextrin complexes prepared by kneading method. Int J Adv Pharm Sci, 2010; 1: 68-74.

Türk CTS, Bayindir ZS, Badilli U. Preparation of polymeric nanoparticles using different stabilizing agents. J Fac Pharm Ankara, 2009; 38: 257-68.

Zhang C, Zhao Bing-Xiang, Huang Y, Wang Y, Ke X, Zhao Bo-Jun, Zhang X, Zhang Q. A novel domperidone hydrogel: preparation, characterization, pharmacokinetic, and pharmacodynamic properties. J Drug Deliv, 2011; 2011: 1-9.

\section{How to cite this article:}

Aboutaleb AE, Abdel-Rahman SI, Ahmed MO, Younis MA. Improvement of Domperidone Solubility and Dissolution Rate by Dispersion in Various Hydrophilic Carriers. J App Pharm Sci, 2016; 6 (07): 133-139. 